\title{
Design Meets Disability Studies: Bridging the Divide between Theory and Practice
}

\section{Dr. Sarah Summers, Rose-Hulman Institute of Technology}

Dr. Sarah Summers earned her PhD in Rhetoric and Composition from Penn State University and joined the RHIT faculty in 2014. Her work focused on writing in the disciplines, particularly at the advanced undergraduate and graduate levels. She teaches courses in writing and engineering communication, including technical and professional communication, intercultural communication, digital writing, and grant writing.

\section{Prof. Renee D. Rogge, Rose-Hulman Institute of Technology}

Renee Rogge is the Samuel F. Hulbert Chair of Biomedical Engineering and Associate Professor of Biomedical Engineering at Rose-Hulman Institute of Technology. She has been teaching at Rose-Hulman since 2004, and her research interests lie in the areas of assessment of engineering design and orthopaedic biomechanics. 


\section{Design Meets Disability Studies: Bridging the Divide between Theory and Practice}

\section{Background}

Disability design teams, usually made up of clinicians and engineers, focus on solving problems ${ }^{1}$. As engineering educators, we know that our students can be excellent at identifying problems. We train them — often through design courses— to solve problems and execute those solutions. But designing for disability benefits from a broader perspective: "A richer balance between problem solving and more playful exploration could open up valuable new directions" (pg. Xv) ${ }^{1}$. This paper describes the design of an interdisciplinary course to be taught beginning in March 2017, Introduction to Disability Studies, that integrates Liberal Arts and STEM perspectives with the goal of creating precisely the balance that Pullin describes.

In the sections that follow, we first describe the design of the course, focusing on the humanities perspectives and assignments that inform the theoretical disability studies framework. This section also addresses our approaches to breaking down perceived divisions between STEM and the liberal arts by linking those perspectives and assignments to broader habits of mind that are necessary for engineers and designers. We then describe our strategies for integrating a rich design experience into the course and consider how that integration alters typical approaches to design projects. Finally, we discuss our plan to implement assessments that account for both students' technical abilities and their application of course theories and concepts.

Course development was supported at the Institution by a summer course development grant that encouraged faculty to partner across disciplines to create unique course offerings. The partnership between the Humanities \& Social Sciences (HSS) and the Biomedical Engineering (BE) departments was a natural fit due to the discipline-specific expertise of the HSS faculty member and the design experience of the BE faculty member. Throughout our creation of the course, our goal is to avoid a design experience that seems - to use a metaphor relevant to disability studies_retrofitted to accommodate liberal arts content. Retrofitted disability accommodations, such as ramps tacked on to an inconvenient side of a building, send the message that disability is "supplemental to society; that it is an afterthought" (pg. 21) 2. Similarly, integrating STEM and the liberal arts, especially given national discourses about the relative importance of STEM education ${ }^{3}$, can leave the liberal arts seeming like little more than a supplement to more important learning. The course design outlined below reflects our best attempts to use the lens of disability students to show STEM and the liberal arts as organic, essential, and generative partners.

\section{Course background and overview}

As an academic field, Disability Studies solidified in the 1990s alongside a social model of disability that rejected biological definitions of "normal" bodies and medical perspectives that identified disabilities as problems to be fixed. As a result, the study of disability fractured, often highlighting conflicts between academic and professional interests ${ }^{4}$. At its foundation, the goal of our Introduction to Disability Studies course is to bridge the chasm between theories and research in disability studies and research and praxis in engineering and design. To achieve this 
goal, we designed a course for STEM students that leverages a common STEM experience-a design project - to help students understand the relevance and application of disability studies (and the liberal arts more broadly) to engineering and design.

Previous scholarship addressing STEM and disability studies has most prominently addressed the importance of redesigning STEM curricula to correct the underrepresentation of students with disabilities in STEM fields ${ }^{5,6}$. The goal of our course is to bring a disability studies perspective to engineering tasks for all students, including needs assessments, concept sketches, and prototyping for an original design. This design experience- - which we discuss in detail in the next section - is preceded by, followed by, and informed by readings and activities that introduce students to disability studies. Our goal was to avoid creating the design experience as the central or most important part of the course with disability studies content tacked on. Instead, we designed a course with liberal arts as its foundation (it is taught in our Humanities and Social Sciences Department) to encourage students to integrate disability studies theories and research as an organic part of the design process.

Introduction to Disability Studies will introduce a range of themes in disability studies, from medical histories and the 1990 passage of the Americans with Disabilities Act to cultural norms in disability communities and the challenges of accessibility in a digital age. Across these topics, there are three pedagogical goals, explored in detail in the following sections, that will help students learn important disability studies theories and concepts and prepare them to bring that knowledge to bear on a design project: 1 . hearing the voices of those with disabilities; 2 . identifying representations of disability that they encounter in their daily lives; 3. Inhabiting, rather than overcoming, discomfort talking about and interacting with disability.

Hearing the voices of those with disabilities

The course begins with an introduction to disability studies as a multidisciplinary field that reframes disability not as a medical problem but as a universal part of the human experience. Students will have the opportunity to reflect on their own experiences with disability, and much of the early course content will include readings and documentaries composed by writers with disabilities to encourage students to develop empathy and approach course topics through the perspective of disabled people. For example, Brenda Brueggemann’s essay “On (Almost) Passing” describes her experience "coming out" as a Deaf professor". Much of the essay takes place in an academic setting, which helps students relate to aspects of the otherwise (likely) unfamiliar experience of a Deaf woman trying to pass as Hearing to succeed professionally. Brueggemann also explains that she attempts to pass not only as Hearing but also as Deaf, acknowledging that deafness is often accompanied by its own norms and valid, vibrant culture ${ }^{7}$. Thus, students begin to understand Deafness as more than a malady to be fixed but as a meaningful part of a person's identity and experience. Through readings like these and accompanying class discussions, students will practice listening to and accounting for the perspectives of those with disabilities_a habit that must inform design for disability.

\section{Identifying representations of disability}

One of the core assignments of the course, the Artifact Analysis, asks students to consider how disability is represented, both positively and negatively, in their daily lives. In these five-minute presentations, which students will deliver throughout the course, students will show an public artifact (an advertisement, a tv clip, song lyrics, part of a policy debate, a toy) that represents 
disability and analyze the representation based on our course readings and discussions. One student might choose to bring in the catalog pages that depict an American Girl doll that wears an insulin pump, another might show a YouTube video of a child receiving a cochlear implant, and a third might play part of 3OH!3's song “Don't Trust Me” that includes the lyrics "Shush, girl. Shut your lips. / Do the Helen Keller and talk with your hips.” As students share these artifacts with their peers, they are honing their ability to see how representation matters in disability studies. The presentation assignment also asks them to look beyond the good/bad representation dichotomy to acknowledge the complexity of disability. Why do we have an emotional reaction when we see a video of a child hearing his mother for the first time? What does that reaction say about how we view deafness and the value of deaf lives? This assignment encourages students to weigh several reactions and responses to representations of disability - a task very similar to brainstorming project concepts during the design process.

\section{Inhabiting discomfort}

Interacting with difference is uncomfortable, and we (along with our students) often attempt to avoid this discomfort by focusing on being polite. Politeness, however, often leads to ignoring disability all together and pretending not to notice that someone has a prosthetic leg or struggles to read aloud in class. In other words, politeness can erase disability and render it invisible. The purpose of this class is to make disability visible, and that task often feels uncomfortable. Course readings and discussions, including opportunities for private reflective writing, will be structured to encourage students to explore that discomfort. For example, one of the course texts, Keywords for Disability Studies includes passages on terms like "crip," "eugenics," "freak," and "sex." Most students would resist the term "crip," but many disabled people find it a more empowering in-group term than that patronizing "handi-capable” or "special” (pg. 46) ${ }^{8}$. Discussions about students' relative comfort with "special” over other, more direct terms makes visible the boundaries that prevent students from acknowledging disability. If, as Pullin suggests, designers need a more "playful" approach to designing for disability ${ }^{1}$ those designers will need to inhabit ideas that might seem uncomfortable or push beyond the boundaries of polite in order to create something new, useful, and pleasing.

\section{Engineering Design \& Introduction to Disability Studies}

Empathy is a critical component of human-centered design, and engineering educators have recognized the need for reaching beyond the technical requirements and thinking more carefully about the people who use the devices being developed ${ }^{11-13}$. Exposure to the arts and humanities offers a partial solution to this dilemma - since the educators in these fields are experts at challenging students to develop excellent listening skills, cultural sensitivity, ethics, and empathy ${ }^{13,14}$. While engineering programs require students to take courses in the arts, humanities, and social sciences, students often compartmentalize these human-centric skills as "liberal arts" skills instead of weaving them into their technical expertise. There are numerous examples of engineering programs or courses that have incorporated arts and humanities into design courses to encourage students to practice integrating human-centric skills with their technical knowledge. ${ }^{15-17}$ A major challenge faced by this approach is that these courses are often seen as design courses and the "soft skills" offered by the arts and humanities faculty are just "add-ons" that the students have to "deal with" and the major deliverable in the course is a product or concept design. The course under development takes advantage of the technical nature of the Institute (i.e. all enrolled students are STEM majors) and infuses a humanities 
course with a design project where they demonstrate their understanding of the various models of Disability Studies and empathy research by incorporating these principles into a design product.

To ensure that students were able to link the course content to their work as engineers and scientists, we incorporated a design experience that required students to draw on their growing understanding of disability and access. The accreditation process for engineering programs requires that students be prepared for engineering practice through a major design experience. This design experience must be based on the knowledge and skills mastered in the curriculum and is expected to incorporate appropriate engineering standards and multiple realistic constraints" ${ }^{9}$. To meet this requirement, most programs require a "capstone design experience" that challenges students to develop a device or product for a diverse group of potential users. Capstone design experiences that focus on designing for individuals with a disability have emerged as a powerful tool for educating and raising awareness among engineering students about disability while reinforcing important technical skills.

To assist students in developing products that rely heavily on their Disability Studies knowledge, we introduced the concepts of Universal Design (UD) and emphasized the goal of simplifying life for all by "making products, communications, and the built environment more usable by as many people as possible at little or no extra cost." ${ }^{18}$ Exposure to UD principles in a field that remains under-represented by individuals with disabilities ${ }^{10}$ helps engineering students design and deliver products and services that are usable by people with the widest possible range of functional capabilities. However, most engineering students' understanding of "disability” is limited and does not allow for the breadth of experience that would result in innovative, and more inclusive, product design. The objective of the Introduction to Disabilities Studies course is to challenge each student's perception of “disability” and expand their product design capabilities beyond the required components of a capstone design experience. Students completed readings about assistive technology ${ }^{19}$ and discussed the impact of a variety of assistive technology devices such as cochlear implants, closed-captioned videos, braille watches, prosthetic limbs, canes, crutches, walkers, etc.

\section{Design project details}

Multidisciplinary student teams were challenged to design and develop a conceptual prototype of a new product for a person with a disability. Specifically, we asked students to focus on a product that encourages full participation in life. We wanted to move students away from solving a problem (e.g., designing a spoon to make it easier for people with tremors to eat) and toward a playful reimagining that would add fun or pleasure into someone's life. Thus, the project is rooted in the idea that people with disabilities deserve to have full, entertaining, enjoyable lives, not just to be able to perform basic necessities.

Due to the short project timeline (approximately 6 weeks from project identification to final presentation) and students' varied previous experiences with the design process, we provided guidance through a series of detailed milestones. Throughout these milestones, which reflect traditional "product development," students incorporated the theories and readings from the Introduction to Disability Studies course to support product design decisions.

Milestone \#1 - Design Opportunities. Each student individually prepared a one-page project proposal. The proposals documented the details of the disability to be addressed 
and included an analysis of the limitations or shortcomings of current solutions on the market. These proposals were publicly available to the class after being reviewed by the instructors.

Milestone \#2 - Proposal Presentation. Each student prepared and delivered a 60second "pitch" to the class with the goal of establishing a product development team.

Milestone \#3 - Project Preference. Product development teams of up to four students were established using project selection cards submitted by the students to the instructors.

Milestone \#4 - Customer Needs, Background Research, and Brainstorming. Product development teams conducted user research, including the perspectives of users with disabilities, created empathy maps, and brainstromed multiple solutions to the design challenge.

Milestone \#5 - Concept Sketches. Product development teams submitted rough sketches and descriptions of how Universal Design Principles strengthened the design ideas.

Milestone \#6 - Concept Rationale \& Prototyping. Product development teams selected a concept and began conceptual prototyping. They developed a rationale for the features of their prototype rooted in their user research and disability studies theories.

Milestone \#7 - Demonstration \& Presentation. Product development teams presented their conceptual prototype through an accessible presentation and commercial.

\section{Challenges of design project integration}

Integrating a design project into an Introduction to Disabilities Studies course is a challenging task. The course is offered through the Department of Humanities and Social Sciences (HSS) and it was important to the instructors that the design project supplement the course material and provide opportunities for connection to, not replacement of, the HSS content. A shortened course syllabus and schedule is provided in the Appendix of this paper to showcase how the design project was used to supplement the course material. To avoid over-shadowing the Disability Studies content, minimal emphasis was placed on traditional design theory and detailed engineering design. Instead, students were encouraged to spend more time viewing design through the lens of a user with a disability and appreciating the importance of respecting and understanding the user. For example, Milestone \#4, Customer Needs, Background Research, and Brainstorming, might typically include generating a list of perceived customer needs and a patent review. For this project, we encouraged students to focus more deeply on customer needs by conducting empathy research-research that allows students to interact with real customers and again hear their voices as they make decisions. Students were encouraged to reach out to community organizations, our institution's accessibility coordinator, and other professionals to make connections that allowed them to meet and listen to their potential customers. We also encouraged them to supplement that research with other first-hand accounts, including memoirs, documentaries, and digital resources like blogs and advocacy pages. The results of this empathy 
research had significant influences on their design, altering them to challenges like cost, comfort, and the desire for some users to blend in with their friends.

\section{Assessment strategies}

This course was developed with funds and professional support from the Kern Entrepreneurial Education Network (KEEN) and has three large-scale course objectives that align with KEEN's 3 Cs that contribute to an entrepreneurial mindset: Curiosity, Connections, and Creating Value. The course objectives state that, as a result of Introduction to Disability Studies, students will

- Demonstrate curiosity about how people with disabilities (deafness, autism, paralysis, etc.) experience the world and how those experiences challenge us to redefine, reconceptualize, and re/design for disability. Students will be able to answer questions like: How does disability studies help us understand the perspectives, motivations, and needs of others?

- Make connections between their STEM work and the field of disability studies. Students will be able to answer questions like: How has science and technology shaped the way we define disability? What does it mean to "treat" disability? What might STEM professionals gain from listening to the experiences of people with disabilities?

- Create value for new and diverse audiences. In particular, students will create a marketable product for a user with a disability. They will also design presentations that are accessible to those with disabilities.

Some of these objectives are easily assessed. For example, a take-home final essay exam might ask students directly "What might STEM professionals gain from listening to the experiences of people with disabilities?” and assess them on their ability to provide a cogent answer using examples and resources from the course. But assessing students' ability to create value for a user with a disability - the crux of the design project-is more difficult. Students must prove not only their ability to design a product but also their ability to do so while applying what they've learned from the course, including intangible skills like empathy. In this section, we outline our assessment plan for the design project as a way of demonstrating how we plan to evaluate both students' technical skills and their learning and application of disability studies concepts.

Thirty percent of students' grade for the design project will come from traditional benchmarks, including concept sketches and prototypes. These milestones will be assessed on how well the projects meet the needs of a disabled user and the clarity, feasibility, and originality of students' ideas. In order to assess their ability to practice the habits of mind the course encourageslistening to complex, diverse perspectives, designing with empathy, inhabiting the uncomfortable - the final product will be assessed in two ways. First, as a group, students will create a fully captioned commercial video advertising their product. In contrast to the overly comical representations of disability in commercials for products like Life Alert, the project will challenge students to represent their product with empathy and show its value and desirability for users. To successfully complete this project, students will need to draw on what they learned from their Artifact Analyses and discussions of disability cultures to create an authentic and 
appealing ad. Rather than judge students' prototype on its success or failure, this approach assesses students' ability to explain why their product has value and demonstrate that value in a way that shows understanding of and respect for their user.

Second, students will deliver an accessible presentation to the class and invited guests, including people with disabilities. During their presentations, students will draw explicitly from course readings and resources to demonstrate how their design process and final product were influenced by what they learned. The presentation will be graded on the accuracy of the use of course concepts and the depth of students' connections between course content and the design process. Thus, this assignment allows the instructors to assess to what extent the connections between STEM and the liberal arts that we designed into the course were made visible to the students.

\section{Conclusion}

In Design Meets Disability, Pullin uses the term “resonant design” to describe design that "addresses the needs of some people with a particular disability and other people without that disability but perhaps finding themselves in particular circumstances” (pg. 93). ${ }^{1}$ In other words, resonant design starts with an opportunity and - in creating thoughtful, user-focused design around that opportunity - blurs previous distinctions between abled and disabled. Similarly, when we created this course, we designed it around an opportunity. We identified the need for engineers to be more empathetic, user-focused designers, particularly when it comes to considering disability. As a result, our course design blurs distinctions between the liberal arts (reading, composing, empathizing) and engineering design (analyzing, prototyping, testing) in a way that creates resonance between the goals and outcomes of both disciplines.

\section{References}

${ }^{1}$ Pullin, G. 2011. Design meets disability. Cambridge, MA: MIT Press.

${ }^{2}$ Dolmage, J. 2008. Mapping composition: Inviting disability in the front door. In C. Lewiecki-Wilson \& B.J. Brueggemann (Eds.), Disability and the teaching of writing (pp. 14-27). Boston, MA: Bedford/St. Martin’s.

${ }^{3}$ Cohen, P. 2016, Feb. 21. A rising call to promote STEM education and cut liberal arts funding. The New York Times. Retrieved from http://nytimes.com

${ }^{4}$ DePoy, E., \& Gilson, S. 2014. Disability studies: Origins, current conflict, and resolution. Review of Disability Studies: An International Journal, 4(4). n.p.

${ }^{5}$ Burgstahler, S., \& Chang, C. 2014. Promising interventions for promoting STEM fields to students who have disabilities. Review of Disability Studies: An International Journal, 5(2). n.p.

${ }^{6}$ Slaton, A.E. 2013. Body? What body? Considering ability and disability in STEM disciplines. Proceedings from $120^{\text {th }}$ ASEE Annual Conference \& Exposition.

${ }^{7}$ Brueggemann, B.J. 1997. On (almost) passing. College English, 59(6). 647-660.

${ }^{8}$ Lewis, V.A. 2015. Crip. In R. Adams, B. Reiss, \& D. Serlin (Eds.), Keywords for disability studies (pp. 47-48). New York, NY: New York University Press.

9"Criteria for Accrediting Engineering Programs, 2016 - 2017." ABET Criteria for Accrediting Engineering Programs 2016- 2017. ABET, n.d. Web. 04 Feb. 2017. Retrieved from http://www.abet.org/accreditation/accreditation-criteria/criteria-for-accrediting-engineering-programs2016-2017/.

${ }^{10}$ The U.S. Bureau of labor Statistics. 2016. Persons with a disability: labor force characteristics- 2015. Retrieved from https://www.bls.gov/news.release/pdf/disabl.pdf 
${ }^{11}$ Schmitt, E. 2016. The Importance of Incorporating Designer Empathy in Senior Capstone Design Courses. Proceedings from the $123^{\text {rd }}$ ASEE Annual Conference \& Exposition.

${ }^{12}$ Hess, J.L. 2016. The Development and Growth of Empathy among Engineering Students. Proceedings from the $123^{\text {rd }}$ ASEE Annual Conference \& Exposition.

${ }^{13}$ Walther, J., Miller, S. E. and Sochacka, N. W. (2017), A Model of Empathy in Engineering as a Core Skill, Practice Orientation, and Professional Way of Being. J. Eng. Educ., 106: 123-148. doi:10.1002/jee.20159

${ }^{14}$ Jones, D.S. 2014. A Complete Medical Education Includes the Arts and Humanities. American Medical Association Journal of Ethics, 16(8). 636-641.

${ }^{15}$ Zoltowski, C. 2010. Teaching Human-Centered Design with Service Learning. Proceedings from the $117^{\text {th }}$ ASEE Annual Conference \& Exposition.

${ }^{16}$ Simpson, T.W. 2013. Integrating Engineering and Arts through Capstone Design: Creative Campus Meets the Learning Factory. Proceedings from the $120^{\text {th }}$ ASEE Annual Conference \& Exposition.

${ }^{17}$ Shetty, D. 2001. Integrating Engineering Design with Humanities, Sciences and Social Sciences using Integrative Learning Blocks. Proceedings from the 108th ASEE Annual Conference \& Exposition.

${ }^{18}$ The Center for Universal Design. Environments and Products for All People. 2008. About Universal Design. Retrieved from https://www.ncsu.edu/ncsu/design/cud/about_ud/about_ud.htm.

${ }^{19}$ Hendren, Sara. 2014. "All Technology is Assistive." Backchannel. Retrieved from https://backchannel.com/alltechnology-is-assistive-ac9f7183c8cd\#.uu8md7613. 


\section{APPENDIX A: CONDENSED SYlLABUS \& SCHEDULE SVI 30: INTRODUCTION TO DISABILITY STUDIES}

\section{Course Description}

This course introduces Disability Studies, a multidisciplinary field that identifies, challenges, and conceptualizes representations of disability. In other words, this course asks you to examine the ways bodies are represented on a spectrum from "normal" to "disabled" and how those representations influence our understanding of what it means to be disabled. Topics in the course will include histories of disability policy, bioethics, contemporary representations of disabilities, and the role of science and engineering in our perceptions of and design for disability.

\section{Course Objectives}

By the end of the course, students will be able to

- Identify and explain key disability studies concepts, terms, and controversies

- Apply disability studies theories to everyday representations of disability

- Create accessible presentations and defend the importance of accessible design

- Forumlate connections between STEM, design, and disability studies

- Design prototypes for diverse users

\section{Required Texts}

In addition to the required books, additional required readings will be available on Moodle. Readings must be completed before the class periods that they are assigned. You are required to have each day's reading with you in class, or you will be counted absent.

Adams, Reiss, and Serlin, Keywords for Disability Studies (978-1-4798-3952-0)

Pullin, Design Meets Disability (978-0-262-51674-7)

\section{Grades and Assignments}

\begin{tabular}{ll}
\hline Artifact Presentation & $15 \%$ \\
Midterm Exam & $15 \%$ \\
Design Project & $40 \%$ \\
Final Exam & $20 \%$ \\
Participation (Reading Responses) & $10 \%$
\end{tabular}

Disability Studies "Show and Tell" Artifact Presentation: With a partner, you will identify and analyze a disability studies-related artifact from the world around you and connect it to our course readings. You will discuss your artifact and analysis in a brief, casual presentation to the class. These presentations will serve as a fun, thought-provoking way to start our classes each week. You will also turn in an individual reflection/summary that accompanies your presentation.

Midterm Exam: This take-home essay exam will ask you to draw explicitly from course materials and your notes to synthesize material from the first half of the course. 
Design Project: In small groups, you will research, design, and prototype a new leisure/entertainment product for a user with a disability. The project will be broken down into several milestones that encourage you to make connections between disability studies theories and the design process. The project will culminate with an accessible presentation about your product, a brief commercial, and a written design document.

Final Exam: On the final day of class, we will screen a documentary about disability. Your take-home final exam will consist of short answer and essay questions that ask you to relate the film to the themes and experiences of the course.

Participation/Reading Responses: To keep you accountable for doing the readings and coming to class prepared with ideas for discussion, you will write brief reading responses throughout the course on any day marked with an $\left(^{*}\right)$ on the syllabus. You may choose how many responses you complete based on your desired participation grade.

\section{Course Schedule}

WEEK 1: INTRODUCTION TO DISABILITY STUDIES

Tuesday

Readings: "Disability Studies: A New Normal" (New York Times)

Keywords: None.

Assignments Due: None.

In-class topics: Introduction to course, assignments, and one another. What is Disability Studies and how does the field approach disability? Watch Re-Framing Disability documentary and discuss. Sign up for Artifact Presentations.

Thursday*

Readings: "Nice Words" (Simi Linton, Claiming Disability)

Keywords: Disability, Medicalization, Crip

Assignments Due: None.

In-class topics: What are the models of disability and where/how do we see them in action? How do we/should we talk about disability? Assign and practice Artifact Presentations.

\section{WEEK 2: HISTORICAL AND INTERDISCIPLINARY PERSPECTIVES ON DISABILITY}

Tuesday*

Readings: "Rights and Rights Denied, 1968 -" (Nielsen)

Keywords: History, Activism

Assignments Due: Artifact Presentations 1 \& 2

In-class topics: Overview of disability history, rights, and activism. View and discuss "The Kids Are All Right" documentary. Discussion and analysis of popular activist groups.

\section{Thursday}

Reading Due: "All Technology is Assistive" (Hendren)

Keywords: Design

Assignments Due: None.

In-class topics: What are the connections between engineering, design, and disability? How have shifting understandings of disability changed/challenged engineering? What STEM resources could help inform our DS work? 
WEEK 3: DISABILITY AND/AS IDENTITY

Tuesday*

Reading Due: “On (Almost) Passing” (Brueggemann)

Keywords: Identity, Passing, Deafness, Cognition

Assignments Due: Artifact Presentations 3 \& 4

In-class topics: How does disability shape (and how is it shaped by) identity? How do the concepts of "passing" and "coming out" relate to disability? Watch and discuss "I Stim Therefore I Am."

Thursday*

Reading Due: "Paralympic Athletes' Least Favorite Word: Inspiration" (New York Times)

Keywords: Rehabilitation

Assignments Due: None.

In-class topics: Panel of local disability experts and service providers. Introduce design assignment and begin discussion of redesigned services and activities for people with disabilities. Discuss and critique tropes like "inspirational" and "special."

\section{WEEK 4: ACCESSIBILITY AND IMAGINATION}

\section{Tuesday*}

Reading Due: "Students with Disabilities Preparing for Postsecondary Education" (Office for Civil Rights); "I'm a College Student with Disabilities. Here's What it's Like" (Huffington Post)

Keywords: Access, Accommodation, Education

Assignments Due: Artifact Presentations 5 \& 6

In-class topics: Disability in higher education. Presentation from Patty Eaton, RHIT Disability Services. Access vs. accommodation.

Thursday*

Reading Due: DMD “Introduction" (p. 1-4) and "Exploring Meets Problem Solving" (DMD)

Keywords: Space

Assignments Due: Artifact Presentations 7 \& 8

In-class topics: Discuss and analyze re-imagined spaces. Introduce Cast Studies on Universal Design (https://www.ncsu.edu/ncsu/design/cud/projserv_ps/projects/pscsud.htm) and brainstrom individual ideas for design project. In-class proposal work time.

\section{WeEK 5: DisABILITY AND DESIGN (PROPOSALS)}

\section{Tuesday}

Reading Due: None.

Keywords: None.

Assignments Due: Proposal Presentation and Handout

In-class topics: Deliver design project proposals. Complete team preference sheet. Discuss upcoming project milestones. Assign take-home midterm exam.

\section{Thursday: FIELD TRIP TO ISU SENSORY GARDEN}

Reading Due: None.

Keywords: Senses

Assignments Due: Midterm Exam due by midnight Friday, April 7.

In-class topics: Field trip to ISU Sensory Garden. Teams/projects posted by end of day. 
WEEK 6: DISABILITY AND DESIGN (EMPATHY RESEARCH)

Tuesday*

Reading Due: "Identity Meets Ability" (DMD)

Keywords: Ethics

Assignments Due: Artifact Presentations $9 \& 10$

In-class topics: Conducting ethical, useful stakeholder research. Discuss empathy research assignment and design project milestones. Review available resources. In-class research time.

\section{Thursday}

Reading Due: None.

Keywords: None.

Assignments Due: Empathy Research, Customer Needs, and Brainstorming Memo (end of day)

In-class topics: In-class project consultations and work time.

WeEK 7: Disability and Design (CONCEPT SKetCheS AND PROTOTYPing)

Tuesday*

Reading Due: "Provocative Meets Sensitive" (DMD)

Keywords: None

Assignments Due: Concept Sketches by Wednesday at noon

In-class topics: Discuss reading.

Thursday*

Reading Due: "Feeling Meets Testing" (DMD)

Keywords: None.

Assignments Due: None.

In-class topics: Discuss reading. Receive feedback on concept sketches and begin prototyping.

WeEK 8: DisAbiLity AND Design (UNIVERSAL DESIGN)

Tuesday

Reading Due: None.

Keywords: None.

Assignments Due: Concept Selection Rationale and Prototype by noon Wednesday

In-class topics: Receive feedback on prototypes. Analyze professional design philosophies. Begin working on presentations, commercials, and design document.

\section{Thursday*}

Reading Due: "Simple Meets Universal” (DMD)

Keywords: Communication

Assignments Due: None.

In-class topics: Discuss universal design, universal design for learning, and best practices for accessible presentations. Watch and discuss "Meet the Normals." Analyze and critique representations of accessible products. Continue work on presentations, commercials, and design documents. 
Week 9: Disability and Design: Product Presentations

Tuesday

Reading Due: None.

Keywords: None.

Assignments Due: None.

In-class topics: In-class work time and project consultations.

Thursday

Reading Due: None.

Keywords: None.

Assignments Due: Presentation of Websites (with commercial) and Prototypes

In-class topics: View and discuss presentations.

WEEK 10: REPRESENTATIONS OF DISABILITY

Tuesday*

Reading Due: "The Ethics of Hodor," (The Atlantic); "Sexless in the City: The Search for Love as a Woman with a Disability" (Huffington Post)

Keywords: Representation, Sex, Sexuality

Assignments Due: Artifact Presentations $11 \& 12$

In-class topics: Discuss representations of disability in popular media as a way to review course concepts and synthesize artifact presentations. Compare and contrast representations of sex and disability in movies and television. Watch and analyze clips from contemporary movies and tv shows to prepare for final exam. Complete course evaluations.

\section{Thursday}

Reading Due: None

Keywords: Technology

Assignments Due: Final Exam due by noon on Saturday, May 20.

In-class topics: Watch documentary and discuss final exam. 